\title{
Impact of basidiomycete fungi on the wettability of soil contaminated with a hydrophobic polycyclic aromatic hydrocarbon
}

\author{
Paul D. HalletT ${ }^{1}$, Nia A. White ${ }^{2} \&$ Karl Ritz $^{3}$ \\ ${ }^{1}$ Scottish Crop Research Institute, Invergowrie, Dundee, DD2 5DA, UK; tel.: +44-1382-562731, fax: +44-1382-562426, \\ e-mail: paul.hallett@scri.ac.uk \\ ${ }^{2}$ SIMBIOS, School of Science and Engineering, University of Abertay Dundee, Bell Street, Dundee DD1 $1 H G$, UK \\ ${ }^{3}$ National Soil Resources Institute, Cranfield University, Silsoe, Bedfordshire, MK45 4DT, UK
}

\begin{abstract}
Polyaromatic hydrocarbons (PAHs) present a challenge to bioremediation because they are hydrophobic, thus influencing the water availability and repellency of soil. The addition of different concentrations of the PAH, anthracene, showed it to induce moderate levels of repellency. We investigated the efficacy of three basidiomycete fungal species on improving the wettability of soil by reducing repellency caused by contamination of soil with $7 \mathrm{ppm}$ anthracene. A microcosm system was used that enabled determination of the impact of fungi on wettability at three locations down a $30 \mathrm{~mm}$ deep repacked soil core. Before incubation with fungi, the contaminated soil had a repellency of $R=3.12 \pm 0.08$ (s.e.). After 28 days incubation, Coriolus versicolor caused a significant reduction in repellency to $R=1.79 \pm 0.35(P<0.001)$ for the top section of the soil in a microcosm. Phanerochaete chrysosporium and Phlebia radiata did not influence repellency. None of the fungi had an effect at $20 \mathrm{~mm}$ depth.
\end{abstract}

Key words: fungi, hydrophobicity, soil, bioremediation, polycyclic aromatic hydrocarbon

\section{Introduction}

Soil fungi may influence abiotic properties of their environment through the production or decomposition of hydrophilic and hydrophobic organic compounds that influence water transport and retention (FEENEY et al., 2006; CzArnes et al., 2000; Roper, 2004). These processes will affect water availability to plants and microbes, pollutant transport through bypass flow, rainfall infiltration and overland runoff, and the stability of the soil structure by reducing slaking stresses imposed by rapid wetting (Hallett \& Young, 1999). They may also promote the biodegradation of hydrophobic contaminants in soil, such as polycyclic aromatic hydrocarbons (PAHs) (JoHNSEN et al., 2005).

Contamination of soil with PAHs may also induce repellency on surfaces coated with these hydrophobic chemicals (Mulligan, 2005). In soil, this will influence water availability to plants and microorganisms, reducing its capacity to support biological processes (CHAUdhry et al., 2005). Many studies have shown that non-native, white-rot, wood decaying basidiomycete fungi are effective at degrading these contaminants in controlled laboratory experiments ( $\mathrm{LI}$ et al., 2005; MolleA et al., 2005). Other studies have shown that treating soil with surfactants reduces repellency levels and accelerates degradation rates (MulligAN, 2005). No study to date has examined the influence of introduced basidiomycetes on repellency levels in PAH contaminated soil.

This study investigated the impact of non-native ligninolytic basidiomycete fungi on spatial changes to soil water repellency in soil contaminated with the PAH anthracene. We evaluated the effectiveness of 3 different basidiomycetes to evaluate whether these organisms improve wettability by reducing hydrophobicity. Three extensively researched basidiomycete species capable of metabolizing PAHs were investigated, namely, the white-rot fungi Phanerochaete chrysosporium, Coriolus versicolor and Phlebia radiata. The studies were conducted in a microcosm system described by WHITE et al. (2000) in which the spatial proliferation of fungi from a defined inoculation point can be assessed. We hypothesised that basidiomycetes will effectively reduce repellency levels in PAH contaminated soil.

\section{Material and methods}

Soil

The soil was derived from undifferentiated sandstone (Carpow series) comprising $71 \%$ sand, $19 \%$ silt, and $10 \%$ clay with a $\mathrm{pH}\left(\mathrm{H}_{2} \mathrm{O}\right)$ of 6.2 . The carbon concentration was 2.83 $\pm 0.1 \%$ (s.e.) and nitrogen concentration was $0.18 \pm 0.00 \%$, resulting in a $\mathrm{C}: \mathrm{N}$ of 16.0. Soil was sampled from the top $100 \mathrm{~mm}$ of a one metre quadrat. The water content at the

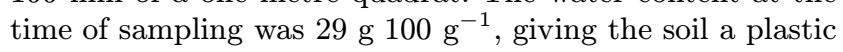


consistency, so before handling it was dried at ambient tem-

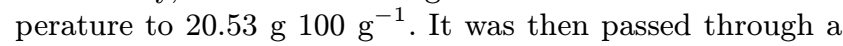
$2 \mathrm{~mm}$ sieve, mixed thoroughly, and stored for 2 days at $4{ }^{\circ} \mathrm{C}$ to improve water distribution.

\section{Fungal inocula}

Cultures of $P$. chrysosporium BURDs. (strain BKMF 1767 MT), C. versicolor (L ex FR) QUELET (strain FPRL 28A) and $P$. radiata (natural isolate from the Forest of Dean, $\mathrm{UK}$ ) were maintained on $2 \%(\mathrm{w} / \mathrm{v})$ malt extract agar (MEA: $20 \mathrm{~g}$ Oxoid malt extract and $10 \mathrm{~g}$ Oxoid agar in $1 \mathrm{l}$ distilled $\mathrm{H}_{2} \mathrm{O}$ ) in plastic Petri dishes at $20^{\circ} \mathrm{C}$.

Microcosm inocula for the sterile soil and natural soil experiments, were prepared by inoculating sterile sand slopes containing $17 \mathrm{~g}$ of acid washed sand and $5 \mathrm{ml}$ of $2 \%$ $(\mathrm{w} / \mathrm{v})$ malt extract (ME: $20 \mathrm{~g}$ Oxoid malt extract in $1 \mathrm{~L}$ distilled $\mathrm{H}_{2} \mathrm{O}$ ) with $5 \mathrm{~mm}$ cores of actively growing MEA cultures. Following incubation for 19 days at $25^{\circ} \mathrm{C}$, the supernatant was prepared according to WHITE et al. (2000), and $700 \mu \mathrm{L}$ portions used as inoculum for each microcosm.

Inocula for the anthracene contaminated soil experiment were prepared by inoculating $1.5 \mathrm{~g}$ portions of a sterilised mixture of hard and soft wood sawdust wetted with $6 \mathrm{ml}$ distilled water, with a $15 \mathrm{~mm}$ core of actively growing MEA culture for 2 weeks.

\section{Polycyclic aromatic hydrocarbon}

Anthracene has been used extensively in studies of $\mathrm{PAH}$ biodegradation in soil (BONNET et al., 2005; JOHNSEN et al., 2005). A 1:30 anthracene to dimethyl sulfoxide (DMSO) stock solution was formed at $80^{\circ} \mathrm{C}$ to facilitate homogeneous mixing of the contaminant in soil. This solution was diluted further with DMSO to provide soil contaminant levels of $0.07,0.7,7$, and $70 \mathrm{ppm}$ anthracene in soil. The amount of DMSO added was kept constant for all anthracene concentrations. Aliquots (12.5 g) of the contaminated soil plus $1.5 \mathrm{~g}$ uninoculated sawdust mixture was packed into a 32 $\mathrm{mm}$ diameter and $10 \mathrm{~mm}$ height plastic ring and then dried at $40^{\circ} \mathrm{C}$. Water repellency was assessed using the approach described below. This provided a calibration of anthracene contamination level versus water repellency for the soil used for the microcosm studies. We used a concentration of $7 \mathrm{ppm}$ anthracene, with soils prepared in the same way described above, for subsequent tests as this induced significant water repellency.

Tests on Petri dishes provided independent verification that the three fungal species could grow in the presence of $7 \mathrm{ppm}$ anthracene. The fungi were first grown on MEA agar plates and then a $10 \mathrm{~mm}$ core was removed aseptically using a cork borer. The core was placed in the centre of a Petri dish split into three isolated sections containing (1) tap-water agar, (2) $7 \mathrm{ppm}$ anthracene mixed homogenously with tap-water agar, and (3) $7 \mathrm{ppm}$ anthracene applied to the surface of the tap-water agar. All ppm measurements are based on the total mass of soil or agar. The last treatment simulated the potential heterogeneous distribution of PAHs on macropore walls in soil, where local concentrations may far exceed levels evaluated for bulk samples. Inhibition of fungi was assessed by visually comparing fungal growth on the contaminated sections with the uncontaminated control section.

\section{Microcosm experiments}

Microcosms consisted of four $32 \mathrm{~mm}$ diameter and $10 \mathrm{~mm}$ height plastic rings that were taped together. The three lower rings of the microcosm were packed with a homogenous mixture of $12.5 \mathrm{~g}$ (wet mass) of soil, $1.5 \mathrm{~g}$ of sawdust inocula and $7 \mathrm{ppm}$ anthracene. The soil had a total porosity of $49 \%$, comprised of $26 \%$ water filled pores, and $23 \%$ air-filled pores. The bottom of the microcosm was sealed with aluminium foil and a sterile foam bung was placed in the top ring, which was not filled with soil, to minimise evaporation. There were five treatments, including each of the 3 fungi species, a control amended with sawdust and a control with no sawdust. Five replicates were formed for each treatment. The microcosms were incubated at $20^{\circ} \mathrm{C}$ in a controlled temperature room for 28 days.

The soil water retention characteristics of a packed microcosm section were evaluated using a Haines Apparatus where water outflow from a saturated sample was recorded over a range of decreasing water potentials. This allowed for the water potential and degree of pore saturation at testing to be determined.

\section{Assessing water repellency}

At the end of incubation, the microcosm sections were separated by cutting them apart with a spatula and then oven dried at $40^{\circ} \mathrm{C}$. The sampling points were the top surface of the top and bottom soil sections. Water repellency was measured using the technique of HALLETT \& Young (1999), which provides quantified data on how hydrophobicity reduces water flow. The approach measures liquid outflow from a small diameter tube $(4 \mathrm{~mm})$ into which a sponge is inserted to provide good soil contact and to allow for the establishment of a negative head. Tests were conducted at a constant head of $-20 \mathrm{~mm}$ to reduce the influence of macropore flow and to allow for the evaluation of sorptivity.

Water repellency, $R$, can be determined from the sorptivity of water and ethanol because the liquids have different liquid:solid surface energies. Ethanol will readily infiltrate into a hydrophobic soil whereas water will not. By taking into account the differences in surface tension and viscosity, $R$ was evaluated as

$$
R=1.95 \frac{S_{\text {Ethanol }}}{S_{\text {Water }}}
$$

where the sorptivity, $S$, is a physical measure of the rate of liquid uptake by the soil (HALleTt \& YounG, 1999). Totally non-repellent soil has an $R=1.0$.

\section{Results}

\section{Fungal growth in the presence of anthracene}

An examination of colony diameters of the fungi in the Petri dish tests provided verification that $P$. chrysoporium, $P$. radiata and $C$. versicolor were not inhibited by $7 \mathrm{ppm}$ anthracene mixed homogeneously with or applied to the surface of tap-water agar. Neither the rate of extension nor hyphal length was diminished by the presence of anthracene $(P>0.10)$. 


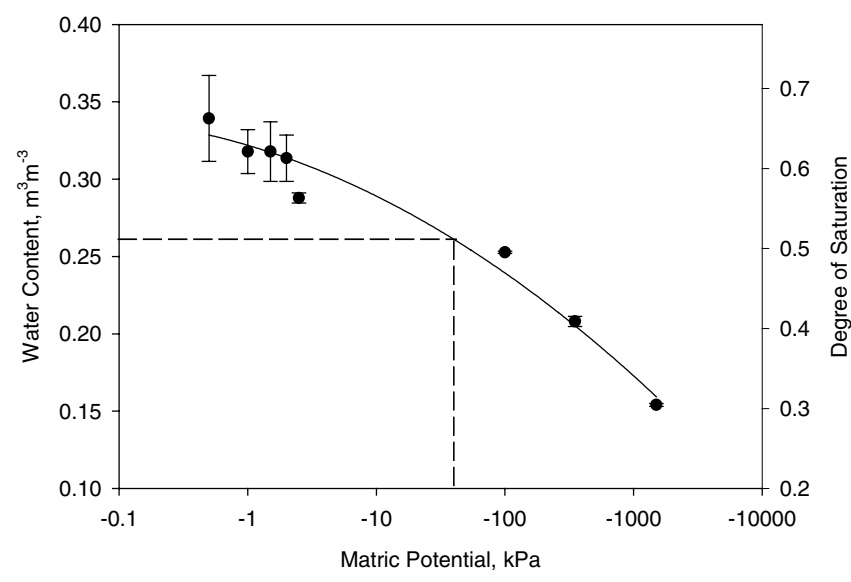

Fig. 1. Water retention characteristics of Bullion Field soil packed into microcosm sections. The dashed line indicates the water content and matric potential of the soil at testing (the standard errors are shown).

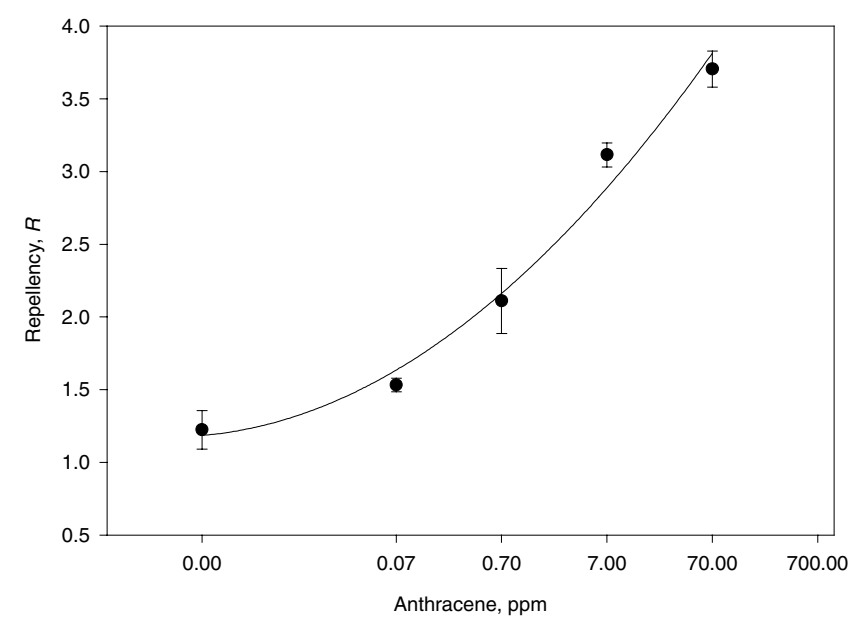

Fig. 2. Influence of anthracene concentration in soil on water repellency (the standard errors are shown).

\section{Soil characteristics}

The water retention characteristics of the soil packed to a density of $1.3 \mathrm{~g} \mathrm{~cm}^{-3}$ in the microcosm are illustrated in Fig. 1. At a water potential of about $-2.5 \mathrm{kPa}$, a secondary stage of drainage occurs. The water content at

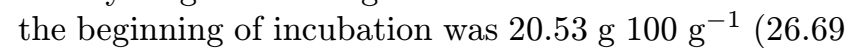
$\left.\mathrm{m}^{3} \mathrm{~m}^{-3}\right)$. This corresponded to a degree of saturation of 0.52 and $-30 \mathrm{kPa}$ matric potential, which will allow for adequate oxygen exchange and water availability to facilitate microbial growth. Water loss from the beginning to end of incubation was less than $2 \mathrm{~g} 100 \mathrm{~g}^{-1}$.

\section{Anthracene}

All statistical analyses used the treatment of soil + sawdust as the control for comparison, as all soils amended with fungi also contained sawdust. Anthracene contamination increased the repellency of the soil examined, with $R$ being highly correlated to the anthracene concentration ( $r^{2}=0.98$, Fig. 2). At $7 \mathrm{ppm}$, repellency

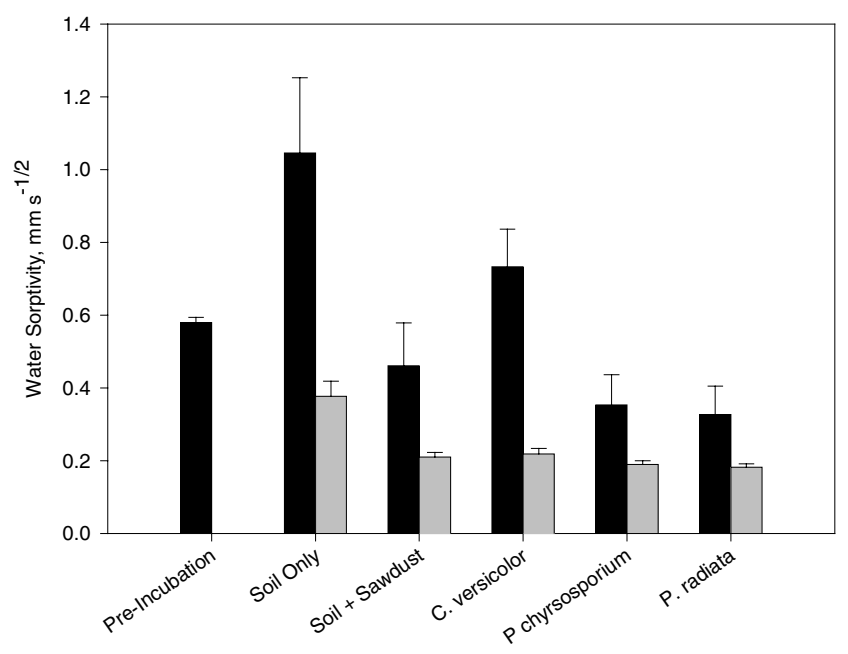

Fig. 3. Influence of inoculation with white-rot fungi on the water sorptivity of soil contaminated with $7 \mathrm{ppm}$ anthracene in upper $10 \mathrm{~mm}$ (black) and bottom $20 \mathrm{~mm}$ (grey) section of microcosm (the standard errors are shown).

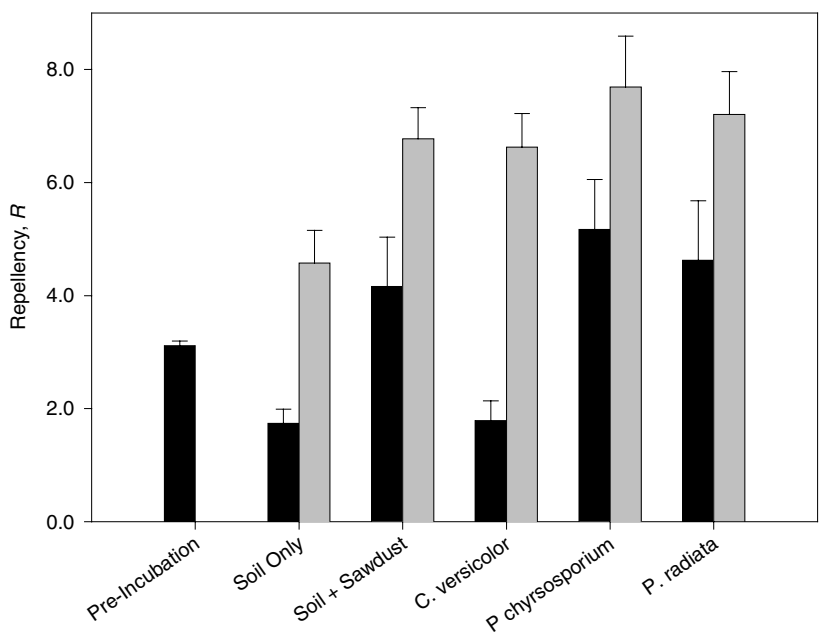

Fig. 4. Influence of inoculation with white-rot fungi on the repellency level of soil contaminated with $7 \mathrm{ppm}$ anthracene in upper $10 \mathrm{~mm}$ (black) and bottom $20 \mathrm{~mm}$ (grey) section of microcosm (the standard errors are shown).

increased by over $250 \%$ with $R>3$, suggesting that reduced water availability may influence biological processes in the soil. In the incubated soil cores, ethanol sorptivity was not significantly different between treatments or location in the microcosm $(P>0.10)$, with an average of $0.82 \pm 0.03 \mathrm{~mm} \mathrm{~s}^{-1 / 2}$. However, water sorptivity varied significantly for both species and location in the microcosm $(P<0.001 ;$ Fig. 3$)$. This was also reflected in the impact on repellency (Fig. 4). Analysis of each location independently shows that there was a significant effect of the fungal species in the top section $(P<0.01)$ but not in the bottom sections $(P>0.10)$ in comparison to the soil + sawdust control. Whilst the microcosms with no inoculum (soil + sawdust), $P$. 
chrysoporium and $P$. radiata have increasing $R$ levels throughout, inoculation with $C$. versicolor reduced $R$ in the top section (Fig. 4). The addition of sawdust also influenced water sorptivity and consequently repellency, but this effect diminished greatest when the sawdust was inoculated with $C$. versicolor.

\section{Discussion}

The increase in repellency caused by contamination with $7 \mathrm{ppm}$ anthracene had an impact on water repellency of the soil, thereby decreasing wettability, the availability of water to microbes and the effectiveness of microbes at bioremediation. This level of contamination did not appear to impede the growth of any of the fungi examined in this study. BONNET et al. (2005) showed that anthracene actually had a fungistatic effect in the presence of $P$. chrysoporium. However, only $C$. versicolor was found to cause a significant reduction in the repellency of anthracene contaminated soil in comparison to the control soil that was amended with the sawdust inoculum but not fungi. This occurred just for the top surface of the microcosm and not at $20 \mathrm{~mm}$ depth, indicating significant spatial variability, probably caused by oxygen availability. Inoculation with $P$. chrysoporium and $P$. radiata did not influence repellency in the top section.

WhITE et al. (2000) found that C. versicolor and $P$. chrysoporium could induce water repellency in soil, with the former species inducing greater levels. This suggests $C$. versicolor can both induce and reduce water repellency depending on the soil environment. It is therefore difficult to relate the changes in water repellency found in this study with the degradation of anthracene. Native and introduced fungi could have induced water repellency through the decomposition of the sawdust inoculum and other carbon sources in the soil (WHite et al., 2000). Specific analysis of anthracene concentrations would be required to determine the effectiveness of the different fungi in the bioremediation of anthracene, although the results suggest that C. versicolor will have the most positive impact on the soil environment. Our study also found that amending soil with sawdust, the carrier that was used for the inocula, caused repellency to increase, possibly because of metabolite production during decomposition of the sawdust by native micro-organisms.

It was surprising that $P$. chrysoporium did not influence repellency, as previous work has found this fungus to be effective at degrading PAHs in soil at concentrations ranging from $7 \mathrm{ppm}$ to $600 \mathrm{ppm}$ (MOLLEA et al., 2005). Research by Novotny et al. (2004) showed that both $P$. chrysoporium and $C$. versicolor produce elevated levels of enzymes that are important to $\mathrm{PAH}$ degradation if grown in PAH contaminated systems.

Research on the bioremediation of PAHs should consider the impact native and introduced organisms on changing water repellency. This is a relatively easy soil property to measure and this information will help understand an improvement of the soil biological environment that could promote $\mathrm{PAH}$ degradation. Moreover, the impact of biosurfactants on repellency requires investigation. Work in this area should also relate the biomass of the introduced and native fungi to changes in anthracene concentration, the production of enzymes important to PAH degradation and water repellency. The effectiveness of other micro-organisms should also be investigated. Wax-degrading bacteria have already been shown by ROPER (2006) to be effective at reducing naturally occurring water repellency so these organisms may also be beneficial to the bioremediation of PAHs.

\section{Conclusion}

The PAH anthracene was found to induce water repellency in soil, which could be lowered by inoculating soil with the white-rot fungus $C$. versicolor. The impact was spatially variable, as surface soil was influenced but not soil at $20 \mathrm{~mm}$ depth. $P$. chrysoporium and $P$. radiata, however, did not influence repellency even on the soil surface, either because these fungal species did not degrade anthracene or produced other hydrophobic substances.

\section{Acknowledgements}

We thank Ian SNOWBALL for technical assistance. The Scottish Crop Research Institute is grant aided by the Scottish Executive Environment and Rural Affairs Department.

\section{References}

Bonnet, J.L., Guiraud, P., Dusser, M., Kadri, M., LafFosse, J., Steiman, R. \& Bohatier, J. 2005. Assessment of anthracene toxicity toward environmental eukaryotic microorganisms: Tetrahymena pyriformis and selected micromycetes. Ecotoxicol. Environm. Safety 60: 87-100.

Chaudhry, Q., Blom-Zandstra, M., Gupta, S. \& Joner, E.J. 2005. Utilising the synergy between plants and rhizosphere microorganisms to enhance breakdown of organic pollutants in the environment. Environ. Sci. Poll. Res. 12: 34-48.

Czarnes, S., Hallett, P.D., Bengough, A.G. \& Young, I.M. 2000. Root- and microbial- derived mucilages affect soil structure and water transport. Europ. J. Soil Sci. 51: 435-443.

Feeney, D., Crawford, J.W., Daniell, T.J., Hallett, P.D., Nunan, N., Ritz, K., Rivers, M. \& Young, I.M. 2006. 3D micro-organisation of the soil-root-microbe system. Microbial Ecology (In press).

Hallett, P.D. \& Young, I.M. 1999. Changes to water repellence of soil aggregates caused by substrate-induced microbial activity. Europ. J. Soil Sci. 50: 35-40.

Johnsen, A.R., Wick, L.Y. \& HARMs, H. 2005. Principles of microbial PAH-degradation in soil. Environ. Pollut. 133: 7184.

Li, P., Li, H., Stagnitti, F., Wang, X., Zhang, H., Gong, Z., Liu, W., Xiong, X., Li, L., Austin, C. \& Barry, D.A. 2005. Biodegradation of pyrene and phenanthrene in soil using immobilized fungi Fusarium sp. Bull. Environ. Contamin. Toxicol. 75: 443-450.

Mollea, C., Bosco, F. \& Ruggeri, B. 2005. Fungal biodegradation of naphthalene: microcosms studies. Chemosphere 60: $\frac{636-643 .}{\text {. }}$ 
Mulligan, C.N. 2005. Environmental applications for biosurfactants. Environ. Pollut. 133: 183-198.

Novotny, C., Svobodova, K., Erbanova, P., Cajthaml, T., Kasinath, A., LAng, E. \& SASEK, V. 2004. Ligninolytic fungi in bioremediation: extracellular enzyme production and degradation rate. Soil Biology \& Biochemistry, 36: 15451551.

Roper, M.M. 2006. Potential for remediation of water repellent soils by inoculation with wax-degrading bacteria in southwestern Australia. Biologia, Bratislava 61(Supl. 19): S358 S362.
Roper, M.M. 2004. The isolation and characterisation of bacteria with the potential to degrade waxes that cause water repellency in sandy soils. Austral. J. Soil Res. 42: 427-434.

White, N.A., Hallett, P.D., Feeney, D., Palfreyman, J.W. \& Ritz, K. 2000. Changes to water repellence of soil caused by the growth of white-rot fungi: studies using a novel microcosm system. FEMS-Microbiol. Lett. 184: 73-77 